\title{
Combination of Multiple Hemodialysis Modes: Better Treatment Options for Patients Under Maintenance Hemodialysis
}

This article was published in the following Dove Press journal:

Therapeutics and Clinical Risk Management

\author{
Zhi-Yong Zhang \\ Ming-Xu Li \\ Hai Yu \\ Jun Zhao \\ Feng-Lin Xiao \\ Fang Xuan \\ Yi-Xin Zhao
}

Department of Nephrology, The Sixth Medical Center of PLA General Hospital, Beijing, People's Republic of China
Correspondence: Ming-Xu Li Department of Nephrology, The Sixth Medical Center of PLA General Hospital, No. 6 Fucheng Road, Haidian District, Beijing 100048, People's Republic of China Tel +86-18600310159

Email Imx1964bw@sina.com
Purpose: Chronic renal failure has become a major public health concern and treatment strategies are urgently needed. We aimed to investigate whether combination of hemodialysis modes was superior to regular hemodialysis for patients under maintenance hemodialysis.

Patients and Methods: A total of 144 patients with end-stage renal failure (ESRF) were enrolled in this single-center retrospective study. Patients received regular hemodialysis (HD) were included in HD group $(n=52)$, patients received regular HD plus hemodiafiltration (HDF) in HD/HDF group ( $n=47$ ), patients received the combination of regular HD, HDF and hemoperfusion (HP) in HD/HDF/HP group ( $\mathrm{n}=45)$. After 1-month and 24-months treatment, therapeutic effects were assessed in terms of nutritional status, control of complications, dialysis adequacy, mean arterial pressure (MAP), infection rate and living quality.

Results: When patients received 1-month treatment, there were no statistically significant differences among three groups. After 24-months treatment, patients in HD/HDF and HD/ $\mathrm{HDF} / \mathrm{HP}$ group presented with better dialysis adequacy, lower MAP and infection rate, higher serum albumin, hemoglobin and calcium levels, lower serum phosphorus and intact parathyroid hormone levels, lower incidence of malnutrition and the Hamilton Depression Scale score, higher the Barthel Index score than HD group $(P<0.05)$. The levels of calcium, phosphorus and intact parathyroid hormone in $\mathrm{HD} / \mathrm{HDF} / \mathrm{HP}$ group were lower than those in HD/HDF group $(P<0.05)$.

Conclusion: Our finding highly indicated that combination of hemodialysis modes was superior to regular HD for patients with ESRF in nutritional status, control of complications, dialysis adequacy, and living quality.

Keywords: maintenance hemodialysis, hemodialysis, hemodiafiltration, hemoperfusion, end-stage renal failure

\section{Introduction}

Chronic kidney disease (CKD), with a progressive and irreversible decline in glomerular filtration rate, has become an important disease threatening global public health. ${ }^{1}$ The typical clinical features are increased serum creatinine level, elevated blood uremia nitrogen, deregulation of salt and water homeostasis, changes in endocrine functions and renal detoxification ability. ${ }^{2}$ In some patients, CKD eventually progress to end-stage renal disease (ESRD). ${ }^{3,4}$ Patients with ESRD are prone to various complications, such as increased risk of cardiovascular disease, infection, malnutrition, metabolic diseases and impaired physical function, and maintenance hemodialysis (MHD) is required to remove toxins and excess fluid. ${ }^{5-8}$ 
MHD is a transitional therapy using hemodialysis (HD) or peritoneal dialysis to save and prolong the life of end-stage patients. HD is a well-established, longterm and life-saving therapy for patients with chronic renal failure (CRF).$^{9-11}$ Regular HD has low or no ability to eliminate middle molecule and macromolecular toxins. Combining the advantages of regular HD and hemofiltration, hemodiafiltration (HDF) not only has a high ability to diffuse and clear small molecules, but also can remove large molecules through hemofiltration. ${ }^{12}$ HDF has been reported to improve toxin clearance in uremia, ${ }^{13,14}$ and reduce the incidence of complications such as conventional hypertension, amyloidosis and accelerated atherosclerosis. ${ }^{15-18}$ Hemoperfusion (HP) is an absorption-based therapy that purifies blood and eliminates immune mediators. Since it does not remove urea, phosphates, water, and electrolytes, it is often used in combination with HD in the treatment of chronic renal failure to remove medium and macromolecular substances. ${ }^{19,20}$

Although the overall survival and quality of life for patients who underwent MHD have improved with the progress of dialysis technology, long-term dialysis treatment has led to an increase in dialysis-related complications. Therefore, it is of great significance to explore how to achieve the best therapeutic effect within the limited dialysis time and frequency, improve the quality of life for patients under MHD, and reduce the occurrence of complications and mortality. In the present study, three different blood dialysis modalities (regular HD, regular HD and HDF, combination of regular HD, HDF and HP) were adopted to compare the clinical effects of long-term treatment with different combinations of dialysis modes.

\section{Patients and Methods}

\section{Patients}

The single-center retrospective study included 144 patients with end-stage renal failure (ESRF) who received MHD treatment in our hospital between January 2018 and January 2020 . The primary disease included various types of glomerulonephritis, diabetic nephropathy, secondary systemic disease, infectious nephropathy, ischemic kidney sclerosis, and interstitial nephropathy of various causes. This study complied with the Declaration of Helsinki and was approved by the Ethics Committee of the sixth Medical Center of PLA General Hospital. All of the enrolled patients signed informed consent.
Inclusion criteria were as follows: the patient's glomerular filtration rate was less than $15 \%,{ }^{21}$ which is the diagnostic criteria for end-stage renal failure in the book Internal Medicine; On the basis of meeting the criteria, patients may also have the following complications related to renal failure: excessive volume load accompanied by uncontrollable malignant increase in blood pressure, electrolyte disorders and acid-base imbalance, mineral and bone disorder, serositis, nutrition deterioration and severe skin itching.

Exclusion criteria were as follows: 1) Patients with serious coexisting diseases, such as viral hepatitis, acquired immunodeficiency syndrome, communicable disease, psychosis, terminal malignant tumors, etc. 2) Patients with severe infections or inflammatory reactions. 3) Patients with severe malnutrition. 4) Patients with intolerance to hemodialysis.

\section{Treatment Regimens}

The choice of dialysis was determined by patients according to their own diseases, personal wishes, economic status, medical security ability and self-care ability. Based on the type of dialysis, 52 patients who received regular HD were included in HD group, 47 patients received regular HD plus HDF in HD/HDF group, 45 patients received the combination of regular HD, HDF and HP in HD/HDF/HP group. Patients in HD group received regular HD three times a week, patients in HD/HDF group were treated with regular HD twice and HDF once a week, patients in HD/ $\mathrm{HDF} / \mathrm{HP}$ group were treated with regular HD twice, HDF once and HP once a week. Patients were treated with different hemodialysis catheter, including human arteriovenous fistula and artificial blood conduit fistula.

Braun Dialysis Equipment (Dialog iQ, German) was used. Treatments were based on 3-times-weekly dialysis sessions, $12 \mathrm{~h} / \mathrm{w}$ per session, with a blood flow of 200 to $500 \mathrm{~mL} / \mathrm{min}$ and a dialysate flow of $500 \mathrm{~mL} / \mathrm{min}$. The main component of dialysate was ultrapure bicarbonatebuffer with a dialysate flow of $500 \mathrm{~mL} / \mathrm{min}$. For dialysis filter, disposable high-flux polysulfone membrane (HF1519) was used in HD, disposable ABH-F series polysulfone membrane was used in HDF and the amount of blood replacement completed in 4 hours with post-replacement mode was 20L. Non-reusable perfusion (HA80, 130g) was selected in HP for 2-hour continuous treatment based on hemodialysis. Patients continued to take prescription drugs to treat other complications caused by dialysis, such as hypertension, anemia, blood glucose instability and body acid-base imbalance. 


\section{Clinical Assessment}

General information and various clinical data of all patients from the beginning of MHD to 1 month were used as baseline values and to 24 months were used as the end point. Mean arterial pressure (MAP) was recorded during each dialysis treatment. The occurrence of infection was recorded at any time and the infection rate was represented as the ratio of the number of hospital admissions for treatment due to body or organ infection to the total number of dialysis patients in each group. Dialyzer clearance of urea multiplied by dialysis time and normalized for urea distribution volume $(\mathrm{Kt} / \mathrm{V})$ was used to evaluate dialysis adequacy.

Blood samples were collected from all patients, these samples were used to measure biochemical parameters in terms of serum albumin (sALB), hemoglobin $(\mathrm{Hb})$, carbon dioxide combining power $\left(\mathrm{CO}_{2} \mathrm{CP}\right)$, potassium $\left(\mathrm{K}^{+}\right)$, calcium $\left(\mathrm{Ca}^{2+}\right)$, phosphorus $(\mathrm{P})$, and intact parathyroid hormone (iPTH). Nutritional status of patients was assessed by sALB level and incidence of malnutrition, incidence of malnutrition was represented as the proportion of patients with subjective global assessment (SGA: 0-3, good nutritional status; $<3$, malnutrition) score greater than $3 . \mathrm{Hb}$, $\mathrm{CO}_{2} \mathrm{CP}, \mathrm{K}^{+}, \mathrm{Ca}^{2+}, \mathrm{P}$ and iPTH levels were used to evaluate the effective control of complications in patients.

Life self-care ability was evaluated with the Barthel Index (BI: 0-20, totally dependent; $21-40$, severe dependency; 41-60, moderate dependency; 61-99, mild dependency; 100, independent). Hamilton Depression Scale (HAMD) was used to analyze the degree of depression ( $>24$, severe depression; 17-24, moderate depression; 8-16, mild depression; <8, no depression).

\section{Statistical Analysis}

Statistical analyses were performed with SPSS software (SPSS for Windows, version 19.0, 2001; SPSS, Chicago, IL). Qualitative data were compared among groups using the $\chi^{2}$ test. The measurement data (presented by mean \pm standard deviation) were tested using one-way ANOVA followed by Student-Newman-Keuls (SNK) test for between-group comparisons. $P$-values of less than 0.05 were considered to indicate a significant difference.

\section{Result}

\section{Baseline Characteristics}

A total of 144 patients in HD group (24 females, 28 males, age: $46.1 \pm 10.7$ years), HD/HDF group (25 females, 22 males, age: $47.6 \pm 11.9$ years), and HD/HDF/HP group (20 females, 25 males, age: $57.5 \pm 13.7$ years) were included in the baseline, with the specific data shown in Table 1. The patients received MHD treatment for 24-149 months, and the mean hemodialysis time was $38.23 \pm 13.04$ months. No significant differences were observed in terms of gender, age, weight, the number of patients with diabetes, hypertension and hospitalization due to vascular access problems among all groups (all $P>0.05$ ).

\section{Effect of Different Treatments Regimens on Nutritional Status}

After 1-month treatment, there were no statistically significant differences in SALB level and incidence of malnutrition among three groups (all $P>0.05$ ). When the patient underwent MHD for 24 months, sALB level (Figure 1) was higher in $\mathrm{HD} / \mathrm{HDF}$ and $\mathrm{HD} / \mathrm{HDF} / \mathrm{HP}$ groups than that in HD group, while incidence of malnutrition was significantly lower (HD: $38.5 \%$; HD/HDF: 25.5\%; HD/HDF/HP: 26.7\%) (all $P<0.05$ ) (Table 2).

\section{Effect of Different Treatments Regimens on Control of Complications}

When the patient underwent MHD for 1 month, there was no significant difference on serum biochemical index in three different groups (all $P>0.05$ ). However, when patients received MHD for 24 months, there were no

Table I Baseline Characteristics of the Patients

\begin{tabular}{|l|l|l|l|l|}
\hline Subjects & HD (n=52) & HD/HF (n=47) & HD/HF/HP (n=45) & P \\
\hline Gender (male/female) & $28 / 24$ & $22 / 25$ & $25 / 20$ & 0.117 \\
Age (year) & $46.1 \pm 10.7$ & $47.6 \pm 11.9$ & $57.5 \pm 13.7$ & 0.901 \\
Weight (kg) $^{\mathrm{a}}$ & $66.7 \pm 10.1$ & $65.3 \pm 12.4$ & $64.8 \pm 11.5$ & 0.462 \\
Diabetes (number, \%) & $33(63.5 \%)$ & $32(68.1 \%)$ & $28(62.2 \%)$ & 0.823 \\
Hypertension (number, \%) & $39(75.0 \%)$ & $37(78.7 \%)$ & $34(75.6 \%)$ & 0.898 \\
Hospitalization due to vascular access problems (number, \%) & $13(25.0 \%)$ & $11(23.4 \%)$ & $10(22.2 \%)$ & 0.949 \\
\hline
\end{tabular}

Note: ${ }^{a}$ Data in mean \pm standard deviation. 


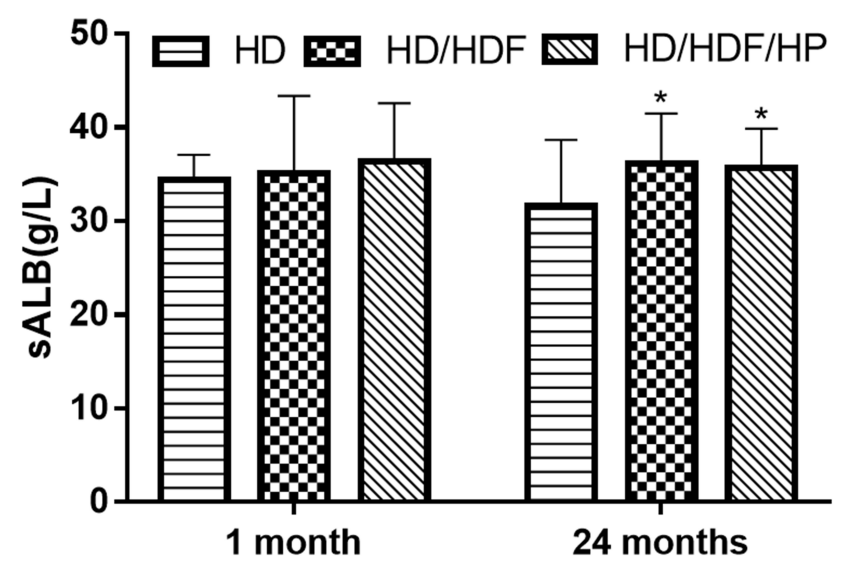

Figure I Serum albumin (sALB) level of different treatments regimens after I month or 24 months of treatment. Regular hemodialysis: HD, HD and hemodiafiltration: HD/HDF, HD/HDF and hemoperfusion: HD/HDF/HP. $* \mathrm{P}<0.05$ vs $\mathrm{HD}$ group.

statistical differences in terms of $\mathrm{CO}_{2} \mathrm{CP}$ and $\mathrm{K}^{+}$in three different groups (all $P>0.05$ ), $\mathrm{Hb}$ and $\mathrm{Ca}^{2}{ }^{+}$were significantly higher in HD/HDF and HD/HDF/HP groups than that in HD group, while $\mathrm{P}$ and $\mathrm{PTH}$ were significantly lower (all $P<0.05$ ). $\mathrm{HD} / \mathrm{HDF}$ and $\mathrm{HD} / \mathrm{HDF} / \mathrm{HP}$ groups exhibited significant statistical differences with regard to $\mathrm{Ca}^{2+}, \mathrm{P}$ and $\mathrm{PTH}$, and the levels of $\mathrm{Ca}^{2+}, \mathrm{P}$ and $\mathrm{PTH}$ were lower in $\mathrm{HD} / \mathrm{HDF} / \mathrm{HP}$ group (all $P<0.05$ ) (Figure 2).

\section{Effect of Different Treatments Regimens on Dialysis Adequacy, Mean Arterial Pressure and Infection Rate}

After 1 month of treatment, there were no statistically significant differences in $\mathrm{Kt} / \mathrm{V}$, mean arterial pressure and infection among three groups (all $P>0.05$ ). When patients received MHD for 24 months, Kt/V of $\mathrm{HD} / \mathrm{HDF}$ and $\mathrm{HD} /$ $\mathrm{HDF} / \mathrm{HP}$ groups were obviously higher in comparison with HD group (HD: $1.12 \pm 0.43$; HD/HDF: $1.65 \pm 0.64$; $\mathrm{HD} / \mathrm{HDF} / \mathrm{HP}: 1.52 \pm 0.71$, while the mean arterial pressure
(HD: $96 \pm 12 \mathrm{mmHg}$; HD/HDF: $92 \pm 11 \mathrm{mmHg}$; HD/HDF/ HP: $92 \pm 14 \mathrm{mmHg}$ ) and infection rate (HD: $48.1 \%$; $\mathrm{HD} /$ HDF: $23.4 \%$; HD/HDF/HP: 22.2\%) were lower than HD group (all $P<0.05$ ). These results revealed that after combinations of hemodialysis mode therapy, an increase in dialysis adequacy, a decrease in blood pressure and infection rate was evident in patients (Table 3 ).

\section{Effect of Different Treatments Regimens on Living Quality}

There were no statistical differences in subjective assessment in terms of BI and HAMD in three different groups after 1 month of therapy (all $P>0.05$ ). When patients received MHD for 24 months, the score of $\mathrm{BI}$ of $\mathrm{HD} /$ $\mathrm{HDF}$ and $\mathrm{HD} / \mathrm{HDF} / \mathrm{HP}$ groups was obviously higher than that of the HD group (HD: $80 \pm 10$; HD/HDF: $84 \pm 9$; HD/ HDF/HP: $88 \pm 8$ ), while the score of HAMD was lower (HD: $13 \pm 4 ; \mathrm{HD} / \mathrm{HDF}: 10 \pm 3 ; \mathrm{HD} / \mathrm{HDF} / \mathrm{HP}: 7 \pm 4$ ) (all $P<0.05$ ) (Table 2).

\section{Discussion}

In the present study, three different hemodialysis methods, regular $\mathrm{HD}$, regular $\mathrm{HD} / \mathrm{HDF}$ and regular $\mathrm{HD} / \mathrm{HDF} / \mathrm{HP}$ were performed on patients under MHD. We emphasized on evaluating the clinical effects of different combinations of hemodialysis modes. Our finding highly indicated that therapeutic efficacy of combinations of hemodialysis mode was superior to the efficacy of regular HD in the treatment of patients with ESRF in terms of nutritional status, control of complications, dialysis adequacy, blood pressure, infection rate and living quality.

Nutritional deficiency is a common complication in patients with $\mathrm{CKD}^{22}$ Patients under MHD during dialysis have protein component loss. ${ }^{23}$ Although serum albumin levels can be affected by other non-nutritional factors such as inflammation, infection, proteinuria, and fluid status, it

Table 2 Comparison of Incidence of Malnutrition, BI, HAMD of Different Treatments Regimens After I Month and 24 Months of Treatment

\begin{tabular}{|l|l|l|l|l|l|}
\hline & Time & HD (n=52) & HD/HDF (n=47) & HD/HDF/HP (n=45) & P \\
\hline Incidence of malnutrition & $\begin{array}{l}\text { I month } \\
24 \text { month }\end{array}$ & $\begin{array}{l}9.6 \% \\
38.5 \%\end{array}$ & $\begin{array}{l}8.5 \% \\
25.5 \% *\end{array}$ & $\begin{array}{l}8.9 \% \\
26.7 \% *\end{array}$ & $\begin{array}{l}0.981 \\
0.048\end{array}$ \\
\hline $\mathrm{BI}^{\mathrm{a}}$ & I month & $86 \pm 7$ & $85 \pm 12$ & $83 \pm 8$ & 0.080 \\
& 24 month & $80 \pm 10$ & $84 \pm 9^{*}$ & $88 \pm 8^{*}$ & 0.041 \\
\hline HAMD $^{\mathrm{a}}$ & I month & $6 \pm 2$ & $7 \pm 2$ & $7 \pm 3$ & 0.112 \\
& 24 month & $13 \pm 4$ & $10 \pm 3^{*}$ & $7 \pm 4^{*}$ & 0.028 \\
\hline
\end{tabular}

Notes: ${ }^{\mathrm{a}}$ Data in mean \pm standard deviation. ${ }^{*} \mathrm{P}<0.05$ vs HD group.

Abbreviations: BI, the Barthel Index; HAMD, the Hamilton Depression Scale. 

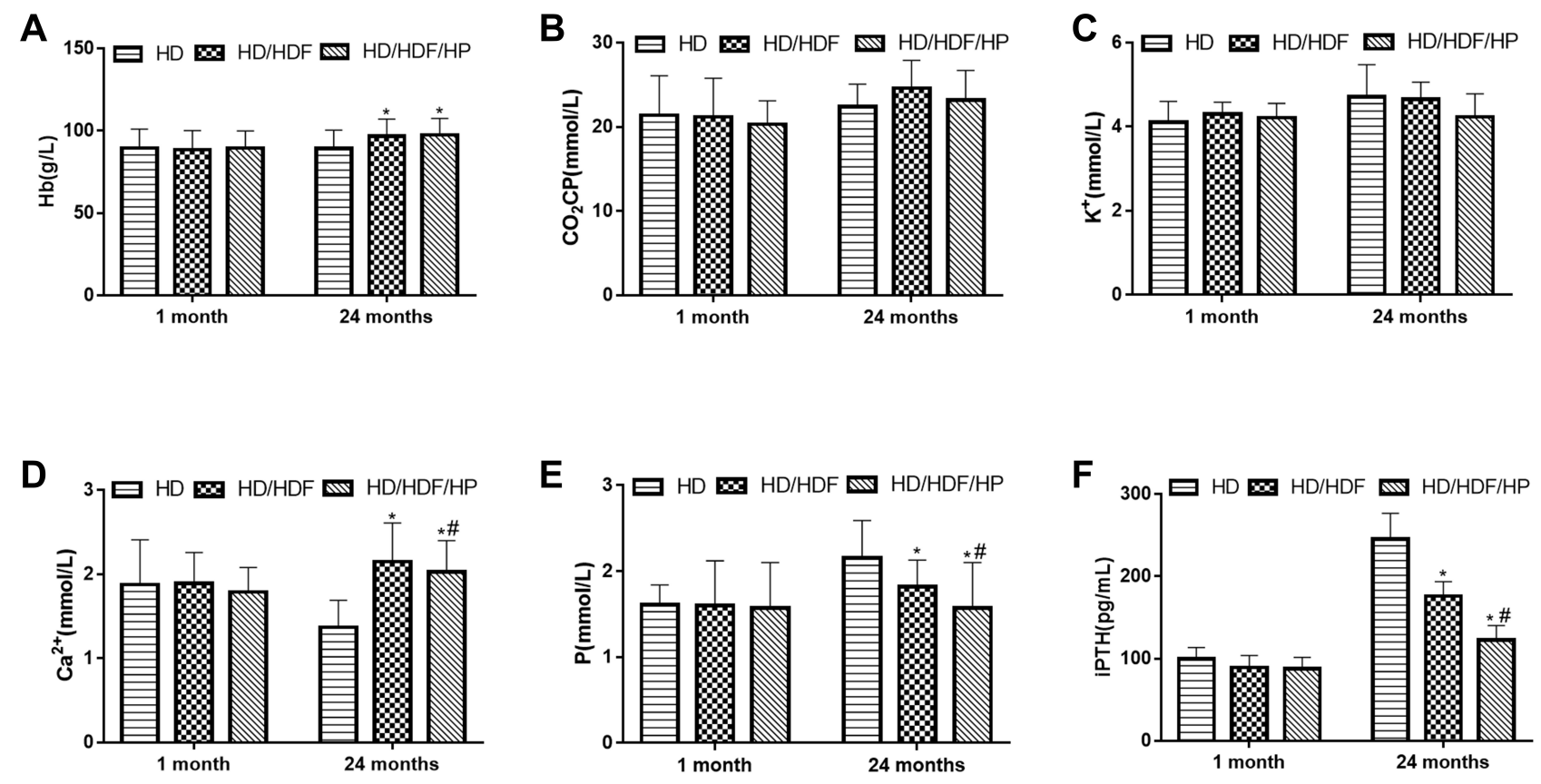

Figure 2 Serum biochemical index related to complication control with different treatments regimens after I month or 24 months of treatment. $(\mathbf{A}) \mathrm{Hemoglobin}(\mathrm{Hb})$, $(\mathbf{B})$ carbon dioxide combining power $\left(\mathrm{CO}_{2} \mathrm{CP}\right),(\mathbf{C})$ potassium $\left(\mathrm{K}^{+}\right),(\mathbf{D})$ calcium $\left(\mathrm{Ca}^{2+}\right)$, (E) phosphorus (P), (F) intact Parathyroid Hormone (iPTH). Regular hemodialysis: $\mathrm{HD}$, $\mathrm{HD}$ and hemodiafiltration: HD/HDF, HD/HDF and hemoperfusion: HD/HDF/HP. ${ }^{*} \mathrm{P}<0.05$ vs $\mathrm{HD}$ group; ${ }^{\#} \mathrm{P}<0.05$ vs $\mathrm{HD} / \mathrm{HDF}$ group.

is widely used as biomarkers of nutritional status in patients with CKD. ${ }^{24,25}$ Our study found that after 24 months of dialysis treatment, serum albumin levels in $\mathrm{HD} / \mathrm{HDF}$ and HD/HDF/HP group was significantly higher than that in HD group and incidence of malnutrition was lower. Low albumin levels in patients with CKD were reported to be associated with malnutrition. ${ }^{26}$ These results indicated that the combination of multiple dialysis modes could delay the loss of nutrients.

One of the key observations of this study was that after 24-months treatment, $\mathrm{Ca}^{2+}$ and $\mathrm{Hb}$ levels in $\mathrm{HD} / \mathrm{HDF}$ and $\mathrm{HD} / \mathrm{HDF} / \mathrm{HP}$ group were significantly higher than those in HD group, while P and iPTH levels were lower than those in HD group. Abnormalities of calcium, phosphorus, and parathyroid hormone are characteristic of CKD and important factors for adverse outcomes in patients receiving maintenance dialysis. ${ }^{27,28}$ For patients with HD, hyperphosphatemia and hypocalcemia are often poorly controlled metabolic consequences of renal failure. ${ }^{29}$ Studies have found that serum $\mathrm{Hb}$ and calcium levels were lower in patients with hemodialysis before death. ${ }^{30}$ Higher Hb concentrations have been shown to be associated with improved symptoms and reduced the need for blood transfusion and/or hospitalization. ${ }^{31}$ Secondary hyperparathyroidism is one of the main complications of ESRD requiring dialysis treatment, and the most typical clinical

Table 3 Comparison of Kt/v, MAP, Infection Rate of Different Treatments Regimens After I Month and 24 Months of Treatment

\begin{tabular}{|l|l|l|l|l|l|}
\hline & Time & HD (n=52) & HD/HDF (n=47) & HD/HDF/HP (n=45) & P \\
\hline Kt $/ \mathrm{v}^{\mathrm{a}}$ & I month & $1.42 \pm 0.32$ & $1.45 \pm 0.35$ & $1.45 \pm 0.74$ & $\begin{array}{l}0.138 \\
\end{array}$ \\
& 24 month & $1.12 \pm 0.43$ & $1.65 \pm 0.64^{*}$ & 9.013 \\
\hline MAP (mmHg) & 1 month & $97 \pm 13$ & $96 \pm 14$ & $97 \pm 16$ & $0.7 I^{*}$ \\
& 24 month & $96 \pm 12$ & $92 \pm 11^{*}$ & $92 \pm 14^{*}$ & 0.016 \\
\hline Infection rate & I month & $3.8 \%$ & $2.1 \%$ & $2.2 \%$ & 0.842 \\
& 24 month & $48.1 \%$ & $23.4 \%^{*}$ & $22.2 \%^{*}$ & 0.008 \\
\hline
\end{tabular}

Notes: ${ }^{a}$ Data in mean \pm standard deviation. $* \mathrm{P}<0.05$ vs HD group.

Abbreviations: $\mathrm{Kt} / \mathrm{v}$, dialyzer clearance of urea multiplied by dialysis time and normalized for urea distribution volume; MAP, mean arterial pressure. 
symptom is elevated parathyroid hormone. ${ }^{32}$ The high-flux membrane was used in our HDF apparatus. The application of high-flux membrane in HDF has been shown to be useful in delaying the occurrence of long-term complications. ${ }^{33}$ Furthermore, the present study also discovered that serum $\mathrm{P}$ and iPTH levels of patients receiving HP treatment were significantly lower than those of patients not receiving HP treatment, indicating that HP was more effective in regulating phosphorus metabolism balance and thyroid function, which may be due to the large adsorption area, fast adsorption rate, the ability to specifically adsorb macromolecular toxins including iPTH during HP treatment. ${ }^{34}$ Our study indicated that the combined mode of hemodialysis was superior to regular HD in controlling the occurrence of complications.

Pulse pressure is associated with mortality in patients with MHD. ${ }^{35}$ Studies of hypertension usually focus on stabilizing components of blood pressure, such as mean arterial pressure (MAP). ${ }^{36}$ Inadequate dialysis is one of the causes of hypertension. Our study found that after 24 months of treatment, patients in $\mathrm{HD} / \mathrm{HDF}$ and $\mathrm{HD} / \mathrm{HDF} /$ HP group had significantly lower MAP and better dialysis adequacy compared with patients in HD group. A previous study showed that adequate dialysis could keep the patient's blood pressure normal or easier to control. ${ }^{37}$ For Infection rates, $\mathrm{HD} / \mathrm{HDF} / \mathrm{HP}$ group was lower than $\mathrm{HD} /$ HDF group. These results suggested that combination of different dialysis modes was more effective than regular HD.

The living quality in patients with MHD following treatment was assessed in terms of life self-care ability and depressive degree, and the results showed that after 24-months treatment, patients in HD/HDF and HD/HDF/ HP group had a better-quality life compared with patients in HD group, with higher BI score and lower HAMD score. Studies have found that high-flux dialysis and HP therapy can significantly improve the quality of life in patients with CRF. ${ }^{33,38}$ These results suggested that combination of different dialysis modes provided a better quality of life for patients.

\section{Conclusion}

The combination of multiple dialysis modes could bring better curative effect and prolong the life of patients. The findings from our study provided evidences for combination of different dialysis modes as treatment regimens superior to regular HD.

\section{Disclosure}

The authors report no conflicts of interest in this work.

\section{References}

1. Wang XF, Zhang BH, Lu XQ, Wang P. Efficacy of different hemodialysis methods on dendritic cell marker CD40 and CD80 and platelet activation marker CD62P and P10 in patients with chronic renal failure. J Clin Lab Anal. 2019;33(3):e22713. doi:10.1002/ jcla.22713

2. Zhao YY, Liu J, Cheng XL, Bai X, Lin RC. Urinary metabonomics study on biochemical changes in an experimental model of chronic renal failure by adenine based on UPLC Q-TOF/MS. Clin Chim Acta. 2012;413(5-6):642-649. doi:10.1016/j.cca.2011.12.014

3. Rosselli D, Rueda J-D, Diaz CE. Cost-effectiveness of kidney transplantation compared with chronic dialysis in end-stage renal disease. Saudi J Kidney Dis Transpl. 2015;26(4):733. doi:10.4103/13192442.160175

4. Palmer SC, Palmer AR, Craig JC, et al. Home versus in-centre haemodialysis for end-stage kidney disease. Cochrane Database Syst Rev. 2014;(11):CD009535.

5. Hsu CY, Ordonez JD, Chertow GM, Fan D, McCulloch CE, Go AS. The risk of acute renal failure in patients with chronic kidney disease. Kidney Int. 2008;74(1):101-107. doi:10.1038/ki.2008.107

6. James MT, Hemmelgarn BR, Wiebe N, et al. Glomerular filtration rate, proteinuria, and the incidence and consequences of acute kidney injury: a cohort study. Lancet. 2010;376(9758):2096-2103. doi:10.1016/S0140-6736(10)61271-8

7. James MT, Quan H, Tonelli M, et al. CKD and risk of hospitalization and death with pneumonia. Am J Kidney Dis. 2009;54(1):24-32. doi:10.1053/j.ajkd.2009.04.005

8. Hailpern SM, Melamed ML, Cohen HW, Hostetter TH. Moderate chronic kidney disease and cognitive function in adults 20 to 59 years of age: third National Health and Nutrition Examination Survey (NHANES III). $J$ Am Soc Nephrol. 2007;18(7):2205-2213. doi:10.1681/ASN.2006101165

9. Jia P, Jin W, Teng J, et al. Acute effects of hemodiafiltration versus conventional hemodialysis on endothelial function and inflammation. Medicine. 2016;95(16):e3440. doi:10.1097/MD.0000000000003440

10. Yasuda H, Uchino S, Uji M, et al. The lower limit of intensity to control uremia during continuous renal replacement therapy. Critical Care. 2014;18(5):539. doi:10.1186/s13054-014-0539-4

11. D'Intini V, Bordoni V, Bolgan I, et al. Monocyte apoptosis in uremia is normalized with continuous blood purification modalities. Blood Purif. 2004;22(1):9-12. doi:10.1159/000074918

12. Canaud B, Vienken J, Ash S, Ward RA. Kidney health initiative HDFW. Hemodiafiltration to address unmet medical needs ESKD patients. Clin J Am Soc Nephrol. 2018;13(9):1435-1443. doi: $10.2215 /$ CJN. 12631117

13. Ward RA, Schmidt B, Hullin J, Hillebrand GF, Samtleben W. A comparison of on-line hemodiafiltration and high-flux hemodialysis: a prospective clinical study. J Am Soc Nephrol. 2000;11 (12):2344-2350

14. Maduell F, Navarro V, Cruz MC, et al. Osteocalcin and myoglobin removal in on-line hemodiafiltration versus low- and high-flux hemodialysis. Am J Kidney Dis. 2002;40(3):582-589. doi:10.1053/ ajkd.2002.34918

15. Nakai S, Iseki K, Tabei K, et al. Outcomes of hemodiafiltration based on Japanese dialysis patient registry. Am J Kidney Dis. 2001;38 (Suppl 4):S212-S216. doi:10.1053/ajkd.2001.27449

16. Locatelli F, Marcelli D, Conte F, Limido A, Malberti F, Spotti D. Comparison of mortality in ESRD patients on convective and diffusive extracorporeal treatments. Kidney Int. 1999;55(1):286-293. doi:10.1046/j.1523-1755.1999.00236.x 
17. Ohtake T, Oka M, Ishioka K, et al. Cardiovascular protective effects of on-line hemodiafiltration: comparison with conventional hemodialysis. Ther Apher Dial. 2012;16(2):181-188. doi:10.1111/ j.1744-9987.2011.01042.x

18. Donauer J, Schweiger C, Rumberger B, Krumme B, Bohler J. Reduction of hypotensive side effects during online-haemodiafiltration and low temperature haemodialysis. Nephrol Dial Transplant. 2003;18 (8):1616-1622. doi:10.1093/ndt/gfg206

19. Kacar CK, Uzundere O, Kandemir D, Yektas A. Efficacy of HA330 hemoperfusion adsorbent in patients followed in the intensive care unit for septic shock and acute kidney injury and treated with continuous venovenous hemodiafiltration as renal replacement therapy. Blood Purif. 2020;49(4):448-456. doi:10.1159/000505565

20. Chen L, Wang Z, Zhai S, Zhang H, Lu J, Chen X. Effects of hemoperfusion in the treatment of childhood Henoch-Schonlein purpura nephritis. Int J Artif Organs. 2013;36(7):489-497. doi:10.5301/ ijao. 5000223

21. Ge JB, Xu YJ, Wang C. Chronic renal failure. In: Wang $\mathrm{C}$, editor. Internal Medicine. 9th ed. Beijing: People's Medical Publishing House; 2018:525.

22. Kovesdy CP, Kalantar-Zadeh $\mathrm{K}$. Why is protein-energy wasting associated with mortality in chronic kidney disease? Semin Nephrol. 2009;29(1):3-14. doi:10.1016/j.semnephrol.2008.10.002

23. Salame C, Eaton S, Grimble G, Davenport A. Protein losses and urea nitrogen underestimate total nitrogen losses in peritoneal dialysis and hemodialysis patients. J Ren Nutr. 2018;28(5):317-323. doi:10.1053/ j.jrn.2018.01.016

24. Gama-Axelsson T, Heimbürger $\mathrm{O}$, Stenvinkel P, Bárány $\mathrm{P}$, Lindholm B, Qureshi AR. Serum albumin as predictor of nutritional status in patients with ESRD. Clin J Am Soc Nephrol. 2012;7 (9):1446-1453. doi:10.2215/CJN.10251011

25. John B, Tan BK, Dainty S, Spanel P, Smith D, Davies SJ. Plasma volume, albumin, and fluid status in peritoneal dialysis patients. Clin J Am Soc Nephrol. 2010;5(8):1463-1470. doi:10.2215/CJN.09411209

26. Kalantar-Zadeh K, Cano NJ, Budde K, et al. Diets and enteral supplements for improving outcomes in chronic kidney disease. Nat Rev Nephrol. 2011;7(7):369-384. doi:10.1038/nrneph.2011.60

27. Block GA, Klassen PS, Lazarus JM, Ofsthun N, Lowrie EG, Chertow GM. Mineral metabolism, mortality, and morbidity in maintenance hemodialysis. J Am Soc Nephrol. 2004;15(8):2208-2218. doi:10.1097/01.ASN.0000133041.27682.A2
28. Tentori F, Wang M, Bieber BA, et al. Recent changes in therapeutic approaches and association with outcomes among patients with secondary hyperparathyroidism on chronic hemodialysis: the DOPPS study. Clin J Am Soc Nephrol. 2015;10(1):98-109. doi:10.2215/ CJN.12941213

29. Hsu $\mathrm{CH}$. Are we mismanaging calcium and phosphate metabolism in renal failure? Am J Kidney Dis. 1997;29(4):641-649. doi:10.1016/ S0272-6386(97)90352-8

30. Song KK, Zhao DL, Wang YD, et al. Analysis of factors associated with death in maintenance hemodialysis patients: a multicenter study in China. Chin Med J. 2017;130(8):885. doi:10.4103/0366-6999.204103

31. Palazzuoli A, Quatrini I, Calabrò A, et al. Anemia correction by erythropoietin reduces BNP levels, hospitalization rate, and NYHA class in patients with cardio-renal anemia syndrome. Clin Exp Med. 2011;11(1):43-48. doi:10.1007/s10238-010-0100-y

32. Davies EW, Matza LS, Worth G, et al. Health state utilities associated with major clinical events in the context of secondary hyperparathyroidism and chronic kidney disease requiring dialysis. Health Qual Life Outcomes. 2015;13(1):90. doi:10.1186/s12955-015-0266-9

33. Tattersall J, Canaud B, Heimburger O, et al. High-flux or low-flux dialysis: a position statement following publication of the membrane permeability outcome study. Nephrol Dial Transplant. 2010;25 (4):1230-1232. doi:10.1093/ndt/gfp626

34. Cai N, Li Q, Zhang J, et al. Antifouling zwitterionic hydrogel coating improves hemocompatibility of activated carbon hemoadsorbent. J Colloid Interface Sci. 2017;503:168-177. doi:10.1016/j.jcis.2017.04.024

35. Klassen PS, Lowrie EG, Reddan DN, et al. Association between pulse pressure and mortality in patients undergoing maintenance hemodialysis. JAMA. 2002;287(12):1548-1555. doi:10.1001/ jama.287.12.1548

36. Nichols WW, Nicolini FA, Pepine CJ. Determinants of isolated systolic hypertension in the elderly. J Hypertens Suppl. 1992;10(6): S73-S77. doi:10.1097/00004872-199208001-00020

37. Abedi-Samakoosh M, Ahangarkani F, Aghaie N, Gholami F, Shirzad M, Naseripour $Z$. The relationship between the adequacy of hemodialysis and laboratory parameters. Chronic Dis J. 2018;5(1):19-27.

38. Chen SJ, Jiang GR, Shan J-P, et al. Combination of maintenance hemodialysis with hemoperfusion: a safe and effective model of artificial kidney. Int $J$ Artif Organs. 2011;34(4):339-347. doi:10.5301/IJAO.2011.7748
Therapeutics and Clinical Risk Management

\section{Publish your work in this journal}

Therapeutics and Clinical Risk Management is an international, peerreviewed journal of clinical therapeutics and risk management, focusing on concise rapid reporting of clinical studies in all therapeutic areas, outcomes, safety, and programs for the effective, safe, and sustained use of medicines. This journal is indexed on PubMed Central, CAS,

\section{Dovepress}

EMBase, Scopus and the Elsevier Bibliographic databases. The manuscript management system is completely online and includes a very quick and fair peer-review system, which is all easy to use. Visit http://www.dovepress.com/testimonials.php to read real quotes from published authors. 